\title{
Saving Smiles Trauma Toolkit launched
}

In December 2017 the Local Professional Dental Network, as part of the Greater Manchester Health and Social Care Partnership, launched the Saving Smiles Trauma Toolkit. This aims to follow in the footsteps of the Dental Trauma Guide and the work of Dental Trauma UK by providing a toolkit and framework for the diagnosis and management of dental trauma in the primary care setting.

The toolkit has been co-authored by a team from Primary Dental Services, Community Dental Services, Public Health England and specialist maxillofacial, paediatric and restorative services. It is full of essential information about best practice in trauma care with algorithms for the

\section{BOOK REVIEW}

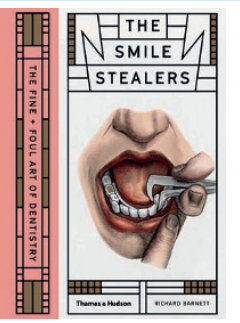

\section{THE SMILE STEALERS}

Richard Barnett, 2017

Thames \& Hudson

price $f 19.95$ pp. 256

ISBN: 9780500519110

The Smile Stealers marks the third in the 'Sick Rose' trilogy, authored by clinician and medical historian Richard Barnett, in partnership with the Wellcome Collection, published by arts publishing firm Thames \& Hodges.

The award-winning series, also known as the 'Illogy', has been praised for its book design, its use of rare and unseen archive material from the Wellcome Collection and Library, and its gruesome yet morbidly beautiful portrayal of medical and surgical advancement through the ages. Being both trained as a medical doctor and a professor of history, Barnett expertly narrates the 'medical history' that has shaped the dental profession from its gruesome origins of the 'tooth puller', through to its modern day format of the skilled clinical service provider and aesthetician of the twentyfirst century.

Book designer Dan Streat continues to employ the exceptional attention to detail that allowed the first of the series, The

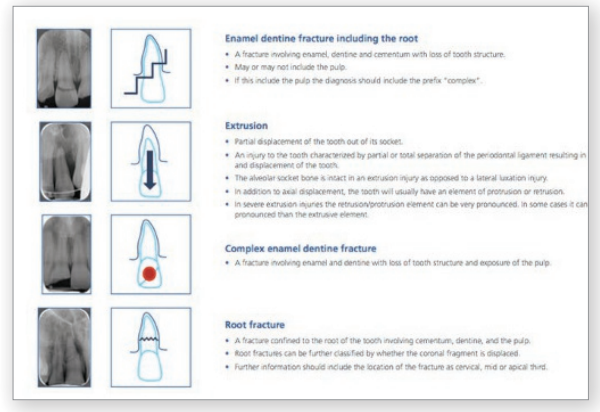

management of differing injuries that can be stored on computer desktops or printed and hung in practices. It also includes information on managing child patients, safeguarding and the longer term consequences of dental trauma.
The ambition is that dentists can and should feel confident managing dental trauma. This will prevent potentially catastrophic delays in care and facilitate the recognition and management of endodontic complications should they arise.

Practitioners wishing to access the guide outside Greater Manchester can sign up at: https://www.dental-referrals.org/mycourses/. Registration is free and practitioners will also find a modular continuing professional education programme with four hours of free certified CPD as they work through the guide.

For more information contact James Darcey at james.darcey@cmft.nhs.uk.

By James Darcey
Sick Rose, to win the British Book Design and Production award in 2014. This latest volume is no less beautiful - bound in an Instagram-worthy colour scheme of offwhite, rosy 'millennial' pink and highlighted with gold debossing, the cover evokes teeth, gums and precious-metal filling materials. Head of Illustrated Reference at Thames \& Hodges, Tristan de Lacey, even states that the geometric themes of the chapter title pages are a reference to Victorian apothecary bottles, and the bite-mark, jaw-hinged end papers are coloured in an 'articulating paper' blue.

This book makes particular reference to the role of Pierre Fauchard, considered the 'father' of modern dentistry, in transforming the image of the gruesome and feared toothpullers into the dentiste, a skilled clinical professional sought out by the self-conscious bourgeoisie of eighteenth century France, who were concerned with attaining the high-status associated with a beautiful mouth full of healthy teeth, described by Barnett as le bouche orneé. What is striking is how this reflects the current-day demand for highquality aesthetic and cosmetic dentistry in a society with an ever-growing obsession with physical appearance and status.

Changes in social and cultural attitudes towards the mouth and disease are explored alongside the more clinical aspects of dental history, such as the role of anaesthesia and the invention of the dental drill. The gruesome medieval art of tooth-pulling is described in detail, with historical excerpts describing the 'malevolent tooth worm', considered to be the cause of tooth pain for hundreds of years before the advent of germ theory. Beautiful depictions of St Apollonia, patron saint of dentistry, accompany an exploration of the religious and spiritual themes surrounding dentistry in the past, while references to modern films and advertising highlight the role that patient-as-consumer has played in shaping dentistry into the global industry we know today.

While dentistry may seem an unconventional topic for a 'coffee-table' book, The Smile Stealers would be fit for a stylish dental clinic waiting room, although may not be the first choice of reading material for the anxious or squeamish patient. But just as high quality dentistry should combine clinical substance as well as good aesthetics, this book is far more than style over substance, and would not be out of place on a BDS curriculum or $\mathrm{CPD}$ reading list, offering the dentist-intraining and qualified professionals alike, a retrospective look at the wider context of the constantly changing culture and values of the dental profession.

Anisha Gupta 